\title{
Training of Student's Social Adaptability by Physical Education Teaching of Higher Vocational College
}

\author{
Feng Li \\ Weifang Medical University, China \\ Email: lifengsdwf@126.com
}

Keywords: Physical education teaching; Higher vocational college; Social adaptability.

\begin{abstract}
The social adaptability has become an important indicator of measuring quality of vocational college students. Its proportion in student comprehensive ability is higher and higher. Therefore, vocational colleges, as teaching institution for cultivating applied special talents, should strengthen cultivation of student's social adaptability. Meanwhile, physical education teaching also should assume cultivation of students' social adaptability. In the paper, important significance of physical education teaching for students to improve social adaptability is discussed, and approaches for physical education teaching to cultivate student's social adaptability.
\end{abstract}

\section{Introduction}

Current century is characterized by knowledge economy, globalization and cultural integration. People have to enhance their social adaptability in order to follow pace of the times and try to adapt to rapid development of society. Vocational college acts as cradle of cultivating high-quality talents, which should shoulder the responsibility of providing high-tech talents for socialist modernization. Therefore, it is required that vocational education should be combined with society, thereby cultivating talents adapting to society. Physical education, as a part of higher education, also should exert its unique influence and role. New physical education curriculum standard in China indicates that we should make efforts to improve students' social adaptability, and continuous improvement of teaching method is required in physical education teaching, different teaching methods are used for enhancing student physical quality and improving students' psychological quality. Meanwhile, we should focus on training students' social adaptability and promoting development of student socialization.

\section{Relationship between College Physical Education Teaching and Students' Social Adaptability}

Physical education can be considered as an objectively existing micro-society with special form in a sense. Physical education itself belongs to an interaction process between teachers and students or among students. In the process, students tend to assume the role of some physical education sport based on specific scenario. Given physical education teaching task can be completed according to certain physical education rule and physical education ethical standards, and it is actually produced by simplifying, concentrating and deforming one social activity, which acts as the earliest contacted social space for students. Students' socialization process is also formed and developed with frequent social interaction in physical education teaching activity process. Thus, college physical education teaching has unique role in the aspects of promoting student individual socialization, and improving students' social adaptability, which is unmatched by other disciplines.

\section{Physical Education's Important Significance for Students to Improve Their Social Adaptability}

Physical Education is beneficial for training interpersonal ability of students with other people . Process of physical education teaching, regardless of physical education class or extracurricular 
physical education activities, is conducted by teachers and students or among students in interaction, communication and exchange. Most physical education activities are undertaken in groups. There are frequent interactions among people. In addition, such exchanges are conducted in open environment, therefore it can better promote communication and exchange among students. Friendly relationship can be established in mutual learning, cooperation and competitive atmosphere, interpersonal emotional experience is enhanced, willing and ability of getting along with other people are cultivated. Therefore, physical education activity has special effect in the aspect of training student interpersonal exchange ability, which can not be replaced by other activities.

In addition, current society does not rely on single force but on team force. Team execution force, performance, effectiveness and performance are available for one team only when cohesion is available. Team cohesion is higher; activity efficiency of the team is higher. Members can make effort for realizing goal of the whole team through mutual attraction, emotion investment and joint cooperation. Various enterprise pay attention to team spirit and cooperation awareness from the perspective of enterprise demand. Physical education activity is mostly carried out by groups in physical education teaching. Win can be achieved in competition through collective cooperation and mutual cooperation especially, which is beneficial for cultivating student team cohesion, group awareness and collaboration capabilities among peers.

Physical education is beneficial for cultivating students' sense of competition. Survival can be achieved in competition, society is developed in competition. Physical education is a course with the highest competition awareness in performance form among various knowledge educations in school. Unyielding and win desiring consciousness shown in each physical education activity and competition process among individuals and teams belongs to refinement of competition awareness once. Cultivation of competition awareness in physical education teaching contains meanings at two levels: firstly, students should dare to compete and work hard in face of difficulties from strong opponents, secondly, we should not be satisfied with ourselves, exceed ourselves constantly, and make effort to new height and extremity. Physical education sports have positive impact on competition sense, which are not available for other disciplines. It is required that we must consciously strengthen education and training on students' sense of competition and make them adapt to society with rapid development through constantly deepening physical education teaching in value orientation of humanity education.

Physical education is beneficial for training students' fighting spirit. More and more students form a 'self-centered' psychological state with increase of one-child proportion in current society, and social affordability is relatively reduced. However, mutual exchange opportunity and interests of students can be increased by competition, students can comprehend own ability and enhance self-confidence. Members in one team always mutually encourage by language or body movements, such as flapping shoulder and clapping hands in group competition, thereby increasing mutual trust and mutual respect emotion as well as sense of team belonging. Impartial and indomitable spirit of students can be cultivated through competition. Development of Students' tenacious, brave and self-expression psychological quality should be developed; good moral characters of teamwork and fair competition can be effectively improved and enhanced through physical education competition activities. In addition, students suffer from failure in physical education competition, the frustration process is also a process of adjusting psychological state, and setback resistance ability is an important aspect of social adaptability. Setback experience caused by the failure belongs to a psychological training and setback withstanding process for students and a process for improving social adaptability.

Physical education teaching is conductive for cultivating students' self-control ability. Physical education sports have confrontational feature, and its most significant feature is strict and thorough competition rule. Although physical education sports competition process is brutal, the whole process reflects fair and equitable physical education spirit. Participants should follow rules of Physical education competition once they participate in the competition regardless of countries, regions and skin color. Each participate should abide by rules of the game consciously in actual 
process of physical education teaching. Competition rules can correct restrict own behaviors, participant violating the competition rules should be eliminated from the competition. The restriction force of Physical education sport can enhance students' self-control ability, especially for those students who are about to cross out of school. The restriction force can be beneficial for cultivating their self-control ability, students can consciously abide by the laws and regulations, adopt legitimate means to participate in social competition, and lay a solid foundation for improving students' social adaptability.

\section{Approach of Physical Education Teaching in Cultivating Students' Social Adaptability}

Improvement of Overall Quality of Physical Education Teachers. Teachers play a leading role in the teaching process; physical education teachers should pay attention to improve their overall quality, actively participate in continuing education and training, strengthen theoretical study of education, psychology and sociology, broaden knowledge scope, and continuously improve knowledge structure, thereby meeting changing quality education and society development demand. Teaching rules can be better mastered through constant learning by themselves. Therefore own experience can be combined for creating many more effective physical exercise and fitness methods. Students' social adaptability can be cultivated subtly in physical education teaching, thereby correctly leading students to the society.

Rational Arrangement of Teaching Contents by Combining with Student Occupational Features . Vocational physical education teaching content should meet the actual needs of the society for talents. Items which are popular among students, and significant for long-term development of students should be introduced in course teaching, therefore contents of vocational physical education teaching can reflect requirements of the era. Meanwhile, teaching contents of vocational physical education should correspond to future occupational post of students, which should strive to realize certain synchronization between student physical development growth and occupational skill improvement. Some items with strong adaptability, which are beneficial for improving students' survival ability, should be arranged in course teaching link. Original course structure should be broken in teaching, thereby realizing change of single physical education course type, constantly enriching teaching system of physical education, and actively adapting to society development demand.

Reation of Micro-society Scenario and Cultivation of Student Social Awareness in Physical Education Course Teaching . Physical education class is actually a miniature of micro-society in certain sense, which is collaborative and competitive with opportunities, challenges, successes and failures. Each person plays a different role in the micro-society. Role cultivation always refers to cultivation of students' understanding on responsibility, obligations and rights in own positions. Students should form a team and become partners with unfamiliar people anytime and anywhere. Partners can be changed into competitors anytime. They can be game players, competitors, partners, enemies, referees, athletes and coaches. Physical education teachers should arrange students' role in exercise, game and teaching game according to teaching contents and students' individual features during teaching. Different tasks should be correspondingly distributed. Meanwhile, student's responsibility in own position should be make clear. Students can complete behavior expected by the group in line with specific role through own effort and peer cooperation under the right given by teacher. Students' understanding on responsibility and obligations can be strengthened, thereby accelerating internalization process of role responsibility thereof, improving social adaptability, and promoting individual socialization, and creating conditions for improving students' social adaptability.

Focus on Implementation of Frustration Education and Improvement of Social adaptability. Teaching of vocational physical education can achieve the exercise and test of students' physical and mind willing through bearing certain physiological and psychological burden at the time of exercise. Frustration has double natures, it can train people's strong will on one hand and guide people to 
summarize experience and learn from lessons, and thereby improving and perfecting own pursuit. It also can make people will depressed with low spirit on the other hand. Therefore, it is particularly important to cultivate students' anti-frustration ability. Teachers should take advantage of competition, contest, test and other forms in physical education teaching, thereby guiding students to challenge difficulty, obstacles and opponents. Guidance, assistance and spiritual encouragement should be timely given to them when they feel fatigue, weak and confused. Cultivation of will quality should be penetrated through physical education classroom, and education constantly internalizing will. Therefore, students can learn to face reality and overcome difficulties with positive attitude in constant exercise.

Enhancement of Students' Survival Awareness Education. College physical education teaching can not be restricted in the classroom and limited in physical exercise, skill improvement, teaching competition and other activities, which should constantly expand physical education teaching contents, innovate physical education activity form, focus on training students' survival ability, and enhance education of survival awareness. In recent years, some colleges set up cross-country orienteering, wild survival and other courses in physical education teaching of colleges, beneficial attempts are conducted with excellent teaching effect. Practice shows that these courses not only can enhance students' physical and mental health, broaden their knowledge scope, increase social experience, and cultivate good moral character, but also can improve students' independent living and practical operation ability, which has important role in cultivating students' social adaptability.

Exertion of 'Rule Effect' in Physical Education Activity and Enhancement of Student Society Standardization. Activities, games and contests in physical education teaching have own specific rules and requirements. Even very naughty students can follow these rules during physical education activity, and they can consciously restrict themselves with rules under the condition without teacher or judges. We always observe that students orderly engage in competition on sports arena. Students violating the rules will automatically hand over the ball control right to opponent party, and the intangible force restricting them is rule. The special 'rule' effect makes students to gradually learn to obey law and respect for the referee during activity, and they can learn to restrict themselves and compete fairly. They know that they must restrain deviant behavior, obey physical education ethics, compete or collaborate with others under the constraints of rules. All these measures play a positive role in training student self-control ability, cultivating law-abiding habit, and complying with social ethics. Therefore, students can better adapt to society in the future.

\section{Conclusion}

Society and people pay more and more attention to overall quality of vocational students with further development and improvement of vocational education in China. Effective positive guidance should be made aiming at the 'social adaptability' especially for vocational student outlook on world, outlook on life, values and handling of heavy learning pressure, employment pressure, etc. during learning. Physical education teaching should not be limited on 'biological effectively' on student physical aspect. Physical education teaching should be regarded as education in common sense, its special effect in cultivating social adaptability should be fully exerted, which is actual purpose for physical education. Influence of physical education on students' social adaptability can not be replaced by other disciplines. Its special effect in cultivating society ability can be fully exerted by continuously exploring and practicing influence and function of vocational physical education teaching activity on student growth process. Vocational physical education should keep with the times constantly, innovate, and adapt to era spirit and society progress, thereby promoting improvement of vocational students' social adaptability.

\section{References}

[1] Zhang Jian. Study on College physical education and the cultivation of students' social adaptation ability[J]. Fujian Sports Science and Technology.2012,31(1):57-59. 
[2] Liu Hua,Liu Jian, Yang Lizhen. The Case is How to Cultivate the Students' Ability of Adapting Society[J]. Journal of Yunnan Normal University(Natural Sciences Edition). 2008, 28 (4): 69-74.

[3] Li Hongxuan. A Discussion on Physical Education in Colleges and Cultivation of Students' Social Adaptability[J]. Journal of Sanming College.2003,2:93-94.

[4] Zhang Xiaojun. The sports teaching to raises the Vocational school student social adaptation ability the exploration[J]. Journal of Hubei Sports Science.2008,6:34-36.

[5] Wang Xin. To implement social adaptation goal in the sports teaching[J]. Journal of Jiamusi Education Institute.2012,2:55-57.

[6] Lv Yujun,Du Changliang,Wang Tongling. Construction of Multiple Integrated "1-3-2" Physical Teaching Model under the Vision of Learning Society[J]. Journal of Jilin Institute of Physical Education. 2013,2:32-33.

[7] Gu Lei, Liu YI. The Target System Structuring of Physical Education Teaching in the Higher Vocational Technical Colleges[J]. Bulletin of Sport Science \& Technology.2012,9:12-14. 